\title{
Ranking Cloud Computing Criteria in Developing Electronic Communications Services Using MCDM
}

\section{Clasificación de los criterios de computación en la nube en el desarrollo de servicios de comunicaciones electrónicas utilizando MCDM}

\author{
Saeid Eslami Mahdiabadi \\ PhD Student of Media Management, Yazd Branch, Islamic Azad University, Yazd, Iran. \\ ORCID: https://orcid.org/0000-0002-4310-2221 \\ Saeed Eslami " \\ Assistant Professor of Media Management, Yazd Branch, Islamic Azad University, Yazd, Iran. \\ ORCID: https://orcid.org/0000-0002-1138-1254

\section{Hossein Eslami} \\ Assistant Professor, Department of Management, Yazd Branch, Islamic Azad University, Yazd, \\ Iran. \\ ORCID: https://orcid.org/0000-0002-0821-1377 \\ Seyed Hassan Hataminasab \\ Assistant professor of Business Management, Yazd Branch, Islamic Azad University, Yazd, \\ Iran. \\ ORCID: https://orcid.org/0000-0002-6473-9053
}

Received 02-08-20 Revised 04-10-20

* Correspondence

Email:saeedeslami@iauyazd.ac.ir
Accepted 01-11-21 On line 01-17-21

\section{Citation:}

Eslami Mahdiabadi S. Eslami S. Eslami H. Hataminasab S. H. (2021). Ranking Cloud Computing Criteria in Developing Electronic Communications Services Using MCDM. Propósitos y $\begin{array}{lll}\text { Representaciones, } & 9 & \text { (SPE1), } 885 . \quad \text { Doi: }\end{array}$ http://dx.doi.org/10.20511/pyr2021.v9nSPE1.885 


\section{Summary}

The main purpose of this study was ranking cloud computing criteria in developing electronic communications services using multiple-criteria decision analysis methodology (MCDM). This correlational research was applied in terms of purpose. Statistical population of the study included ICT experts of the steel industry in Yazd province (industrial experts), among which, 312 individuals were selected using purposeful nonprobability (judgmental) sampling method. Considering the conducted investigations and critically reviewing the related books and articles, the variables, criteria, and scales were identified using cloud computing technology. To analyze the data, MCDM and fuzzy logic calculations were utilized in Expert Choice software. According to the results and considering fuzzy calculations related to the capabilities of cloud computing in developing electronic communications services, the most important criteria in the "IT management in steel industries" cluster having (A) network code was "communicating with steel industries` costumers" having $(\mathrm{AB})$ network code and fuzzy network weight equal to 0.096; the most important criteria in "cloud computing capabilities" cluster having (B) network code were "reducing steel industries' costs" having (BA) network code and fuzzy network weight equal to 0.191; and "providing rapid services to steel industries` costumers" having (BB) network code and fuzzy network weight equal to 0.120 . on the other hand, the most important criteria in "developing electronic communications services" cluster having (C) network code was "storing the data in electronic communications services" having (CD) network code and fuzzy network weight equal to 0.123 , since based on fuzzy logic calculation, they had the highest fuzzy rank in Matlab programming environment regarding cloud computing capabilities in developing electronic communications services.

Keywords: Cloud computing, Electronic communications services, Multiple-criteria decision analysis methodology (MCDM), Fuzzy logic, Steel industries of Yazd province.

\section{Resumen}

El objetivo principal de este estudio fue clasificar los criterios de computación en la nube en el desarrollo de servicios de comunicaciones electrónicas utilizando la metodología de análisis de decisiones de múltiples criterios (MCDM). Esta investigación correlacional se aplicó en términos de propósito. La población estadística del estudio incluyó a expertos en TIC de la industria del acero en la provincia de Yazd (expertos industriales), entre los cuales, se seleccionaron 312 individuos utilizando el método de muestreo intencional no probabilístico (enjuiciador). Considerando las investigaciones realizadas y revisando críticamente los libros y artículos relacionados, las variables, criterios y escalas se identificaron utilizando tecnología de computación en la nube. Para analizar los datos, se utilizaron MCDM y cálculos de lógica difusa en el software Expert Choice. De acuerdo con los resultados y considerando cálculos difusos relacionados con las capacidades de la computación en la nube en el desarrollo de servicios de comunicaciones electrónicas, el criterio más importante en el clúster "Gestión de TI en industrias siderúrgicas" que tenía un código de red (A) era "comunicarse con los clientes de las industrias siderúrgicas" tener un código de red $(\mathrm{AB})$ y un peso de red difusa igual a 0.096; los criterios más importantes en el clúster de "capacidades de computación en la nube" con código de red (B) eran "reducir los costos de las industrias del acero" con un código de red (BA) y un peso de red difuso igual a 0,191 ; y "proporcionar servicios rápidos a los clientes de las industrias del acero" con un código de red (BB) y un peso de red difuso igual a 0,120 . Por otro lado, el criterio más importante en el clúster de "desarrollo de servicios de comunicaciones electrónicas" con código de red (C) era "almacenar los datos en servicios de comunicaciones electrónicas" con código de red (CD) y peso de red difuso igual a 0.123 , ya que basado en cálculo de lógica difusa, tenían el rango difuso más alto en el entorno de programación Matlab 
con respecto a las capacidades de computación en la nube en el desarrollo de servicios de comunicaciones electrónicas.

Palabras clave: Computación en la nube, servicios de comunicaciones electrónicas, metodología de análisis de decisiones de múltiples criterios (MCDM), lógica difusa, industrias siderúrgicas de la provincia de Yazd.

\section{Introduction}

"Information and Communications Technology (ICT)", as the axial technology in the information age, can create the infrastructure of an intelligent city (Jalali Aghdam \& Khademi Shoja, 2018). Business and electronic trading is an appropriate model for creating entrepreneurship and citizen`s business in an intelligent city. Social trading, as well, refers to electronic trading which is based on social media (Doane Ashley, 2016) and (Kim, 2018) and (Al-Muhtadi, 2019).

In today`s growing and electronically interconnected world, human life is on the hands of packs moving with light speed and the result of transmitting such packs includes receiving and sending information from voice and image files to the massages and books or from controlling organizational accounts to trading goods. Such transmissions that form our electronic life, are divided into various sections. For example, they refer to some organizational works done electronically, through internet banking or electronic banking. Therefore, it could be considered as a subset of business and electronic trading (Lussier, 2016) and (Lin, 2019).

Considering the fact that in today`s competitive world, economic factors, as well as social factors, affect businesses, social communication networks play a significant role as a social feature and a driving and basic force for social cohesion in electronic trading (Asadi \& Akbari, 2018) and (Jalali Aghdam \& Khademi Shoja, 2018).

Most of the researchers believe that the final purpose of "quality" is almost meeting the needs and surpassing "costumers`expectations". One of the options of the government for improving the quality of electronic communications services and its variations is using ICT and internet government (Roy, 2012).

Recent years have been the years of the world`s entrance to the "information age", which have changed the economic, social, and cultural aspects of human life. One of the dimensions of this change entails acute changes that have been formed in the economic relationship between individuals, businesses, and governments (Malekian \& Alipour, 2012) and (Bahremand \& Jalali Farahani, 2014).

Trading exchanges among people, businesses, and among people and businesses as well as governments with each other have rapidly changed its traditional form which was mainly based on paper-based and documentary trading and have tended to move toward trading based on using electronic information systems. Electronic trading has opened new ages in the competition due to the speed, efficiency, reduction of costs, and using impermanent opportunities to the extent that postponing such an excursion wouldn't have a result other than being isolated from the world's economic age (Roy, 2012) and (Turkanović \& Gregor, 2013) and (Zulkepli Zuraida, 2015).

Considering the criteria such as developing knowledge regarding the investigation of cloud computing capabilities in improving information conversion in electronic communications services, the investigation of cloud computing capabilities in improving information storage in electronic communications services, investigation of cloud computing capabilities regarding the improvement of information processing in electronic communications services, investigation of cloud computing capabilities regarding the improvement of information recovery in electronic communications services as well as lacking a model for presenting suggestions to the manager for making decisions regarding the issues of investigating 
cloud computing capabilities in developing electronic communications services of steel industries of Yazd province, the conduction of such research seems necessary.

\section{Background of the Study}

(Yagoubi et al., 2014) study investigated the issue that cloud computing, as a new technology having internet substructure and new approaches, could have significant advantages in presenting medical services. Investigating the literature of the subject and based on technological, business, environmental and human fitness models, 16 sub-criteria were identified in 4 the form of main factors; these factors and sub-criteria were ranked through sounding from 60 experts, university professors, and technical experts of data and information health using fuzzy analysis hierarchy process (FAHP). The results of the study indicated that experts believe that technological, humane, organizational, and environmental factors should be considered while making decisions regarding the use of cloud computing in electronic health.

Moreover, (Bahremand \& Jalali Farahani, 2014) investigated that whatever was named "eavesdropping" in the past regarding receiving telephone calls of people illegally, now entails an endless scope of internet data that is prevalent in electronic exchanges. Although it has been almost four decades passing from recognizing electronic communications in local rules, comprehensive penal support of them against unjust conflicts is less than six years.

The current study investigated the constituting components of eavesdropping crime and explored the legal documents of this field with an emphasis on 730 articles of the Islamic Penal Code, thus, it could be concluded that the existing rules had appropriate generalizability. Therefore, some adjustments can be done in determining penal responses to increase rule deterrence.

It has been investigated in (Khatamzadeh \& Tajfar Gheisari, 2016) study that the third wave of the information age, known as comprehensive computing, identified the theory that the technology has used wireless sensors and intelligent networks to make relations with things through the internet of things; this relationship was expanded with the growth and development of technology. Simultaneous with the development of this technology in storing and editing the information having a high volume, cloud computing came to exist with the capability of having access to information and communication technology sources at any time and place. This technology has the capability of productivity and use in most of the management fields. One of these applications in management is assets. Using internet of things in the field of mega information, such problems of asset management could be defeated. Controlling assets intelligibly can lead to the optimal use of assets having other prominent effects such as saving and reducing business costs.

(Bruin, 2018) in a study entitled "the map of informational resources using cloud computing" suggested a multimedia relational algorithm with conscious stability for the internet of transportation devices, which controls multimedia relationship to a certain scope and integrates it with transferred multimedia information of devices that had to be regulated.

Finally, the clustered structure of the network was done through maximizing data sharing and stable multimedia relations. Some experiments of the comprehensive simulation were done for evaluating the performance of the suggested algorithm regarding network stability, final relational delay`s mean, and the rate of packet wastage.

(Xia, 2017) analyzed foggy clouds as a layered cloud platform for online users in the social internet of unknown things. This article focused on the ability $f$ service for observing relational metadata, which could be used for learning the identity and behavioral patterns of users. Therefore, a new system of foggy clouds has been suggested as a platform for creating unknown internet connections for considering security and performance issues. Performance evaluation shows that the appropriate level of being unknown can be obtained through a tolerable performance load. Using comparative analysis, it has been shown that the new algorithm acts better than the existing algorithm. Moreover, features that can facilitate the growth of foggy clouds in a private protective limit, have been discussed. Besides, a user explored the comprehension and attitude of users. 
(Sathya, 2019), analyzed wireless sensory networks for having electronic communications using cloud services. This article sought to reduce the delay time and improve the network's relational efficiency. Firstly, a network having lots of transportation devices was created. It was concluded that electronic communications were mostly misunderstood and public people had to be aware of the security dangers and private limits.

(Farhadian, 2019) investigated cloud computing and concluded that it is a hopeful technology that makes the processing of many data possible. This study sought to present and optimally allocate virtual devices to physical hosts using competitive imperialistic and genetic algorithms. In this regard, intersection operations were integrated from GA to IC. Cloudsim software was also used for simulating and Netbean software was utilized for administration. Significant improvement was obtained in using energy through the suggested method.

\section{Materials and Methods}

The current correlational study was applied in terms of purpose. Statistical population of the study included ICT experts working at the steel industries of Yazd province (industrial experts); among which, 312 individuals were selected using purposeful nonprobability (judgmental) sampling method. Considering the investigations and critical interviews of the books and articles related to the use of cloud computing technology, firstly, variables, criteria, and scales were identified (Table 1).

Investigated variables had been utilized in (Pedhadiya Mittal, 2019) and (Al-Muhtadi, 2019) and (Kim, 2018) and (Lin, 2019), (Jokar \& Berahmand, 2009), (Xia, 2017) and (Sheel Ghulee $t$ al., 2014) and (Sadeqi, 2010) studies as shown in the following (Figure 1):

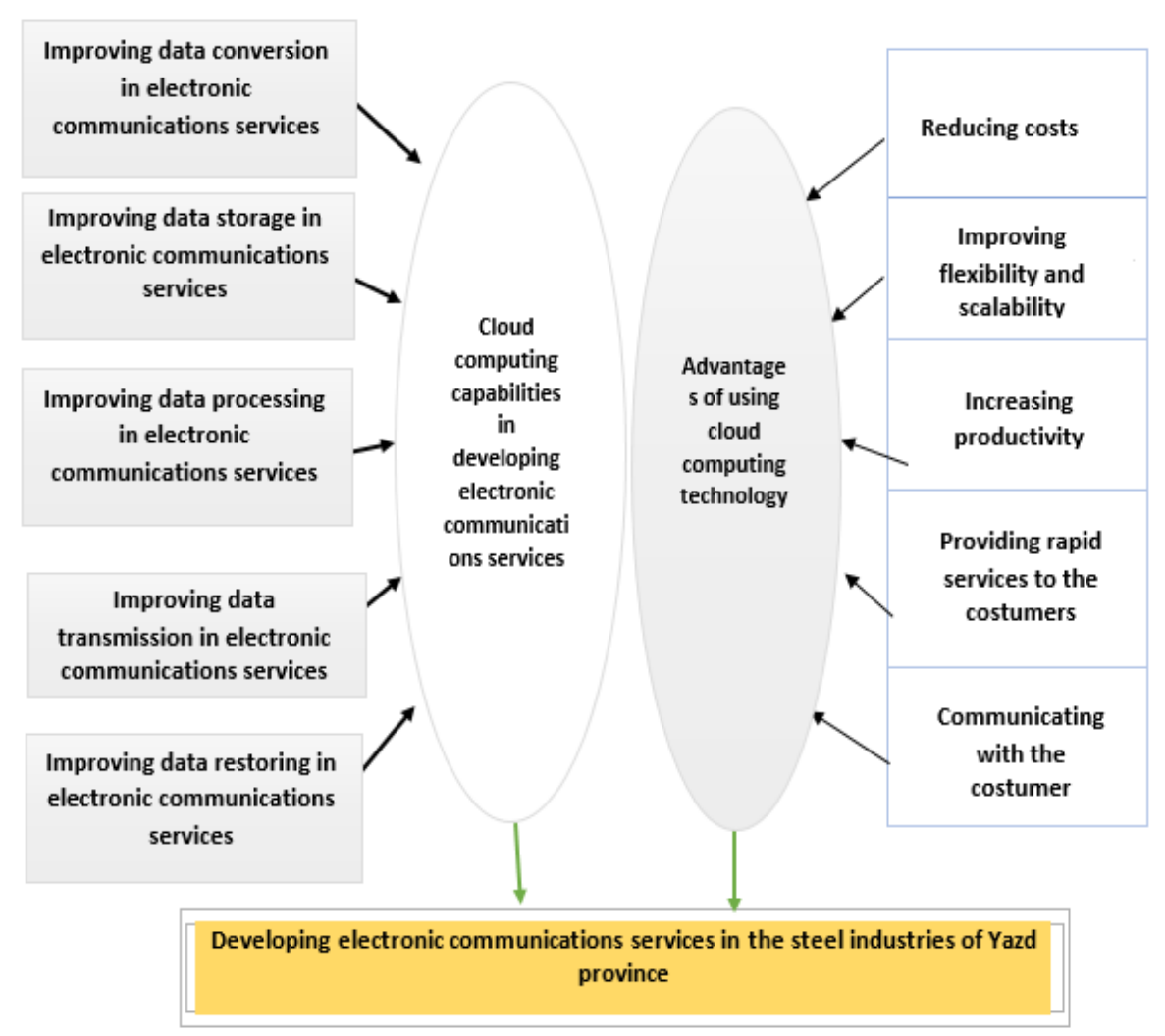

Figure 1. The primary model of investigating cloud computing capabilities in developing electronic communications services

Table 1. 
The final theoretical framework of the study (after confirming the validity of the research model by experts)

Developing electronic communications Cloud computing capabilities component services component

A. (1) Restoring the data in electronic B. (1) Reducing steel industries ' costs communications services

The speed of data recovery $\quad$ Reducing business costs in the hardware section

Quantitative accuracy of data recovery

Reducing business costs in the software section

Qualitative accuracy of data recovery

Reducing business costs in the human forces section

A. (2) Data transmission in electronic communications services

Data transmission volume

B. (2) Providing rapid services to the steel industries` costumers

Developing rapid services and products to the costumers

Data transmission rate

Presenting rapid services and products to the costumers

Data transmission type

Presenting services independently or as a group

A. (3) Storing the data in electronic communications services

Storing costumers`information

Storing business information

Storing competitors`information

A. (4) Information conversion in

electronic communications services

Converting the data to the information

Converting the information to the knowledge

Converting the knowledge to wisdom

IT management component in steel industries

C. (1) Information processing in steel industries

Subject variations (qualitative) of the information

Generalizability (quantitative) of the information

Graphical analysis of the information

C. (2) Interacting with steel industries' costumers

Having a better insight of the costumers

Making the payments among buyers and sellers easy

Sharing organizational programs

Finally, the research data were collected using measurement tools of comparing decision making options of DEMATEL to rank cloud computing capabilities in developing electronic communications services inside seven-point fuzzy logic calculations. Data was analyzed in 
Expert Choice software. This software is used for solving the problems related to the evaluation technique of decision-making options or DEMATEL.

\section{Results}

(Figure 2) and (Table 2) show the ranking based on the causal relationships between the drawings of the effect of cloud computing capabilities in developing electronic communications services.

\section{Synthesis with respect to: MCDM Ranking}
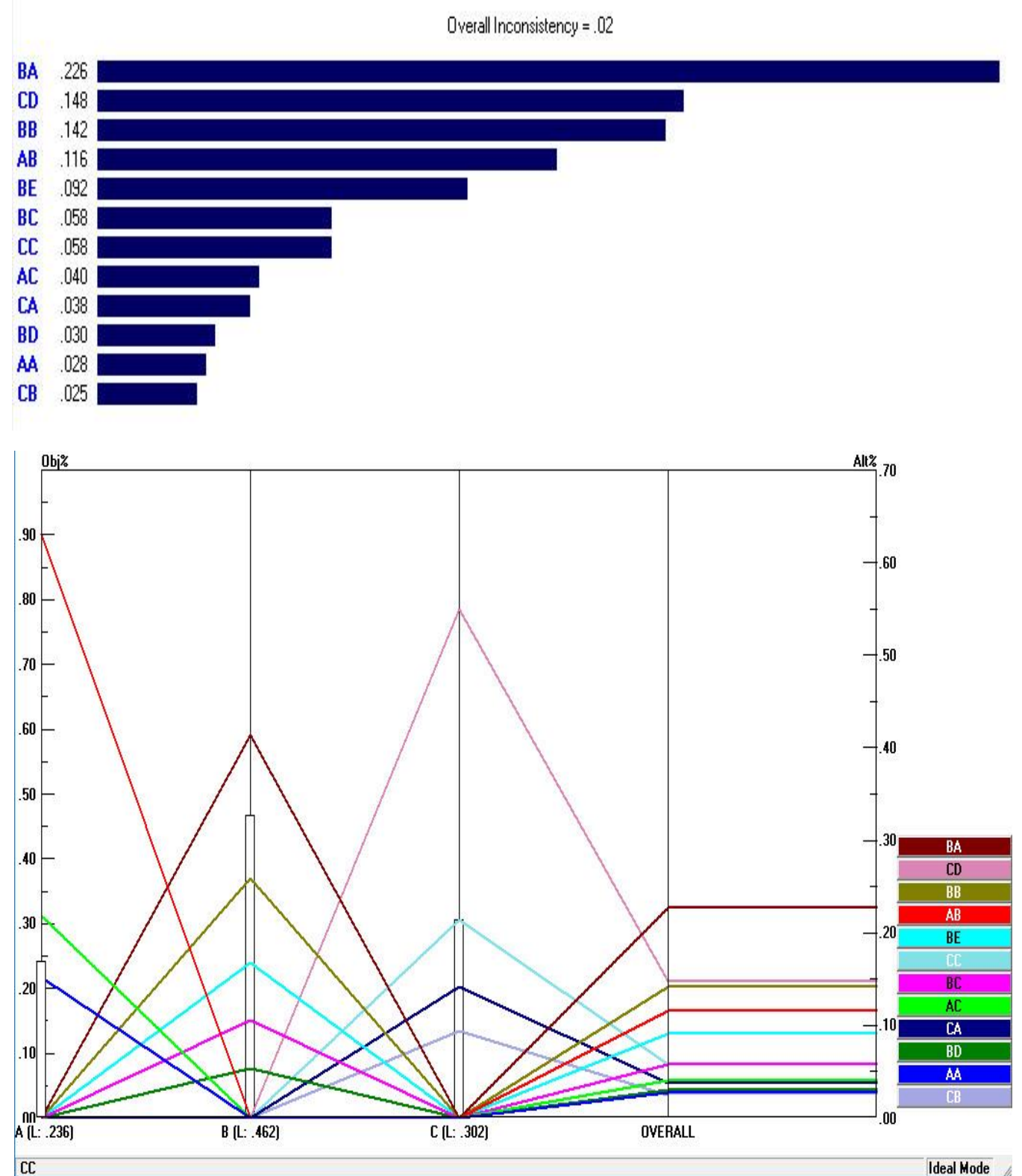

Figure 2. Ranking casual relationships between the graphs regarding the effects of cloud computing capabilities in developing electronic communications services 
The incompatibility rate in the current study is a device that identifies the compatibility and shows the extent that the resulting priorities of the comparisons could be trusted. The above figures show the final analysis and investigate cloud computing capabilities in developing electronic communications services having the least incompatibility rate of 2 (which is 0.02 ).

Table 2.

Ranking research criteria

\begin{tabular}{|c|c|c|}
\hline Rank & Research criteria & $\begin{array}{l}\text { Weight of the } \\
\text { criterion }\end{array}$ \\
\hline 1 & Reducing the costs of steel industries & 0.226 \\
\hline 2 & $\begin{array}{l}\text { Storing the information in electronic communications } \\
\text { services }\end{array}$ & 0.148 \\
\hline 3 & $\begin{array}{l}\text { Providing rapid services to the costumers of steel } \\
\text { industries }\end{array}$ & 0.142 \\
\hline 4 & Communicating with the costumers of steel industries & 0.116 \\
\hline 5 & $\begin{array}{c}\text { Improving the flexibility and scalability of steel } \\
\text { industries }\end{array}$ & 0.092 \\
\hline 6 & Intelligent transportation & 0.058 \\
\hline 7 & $\begin{array}{l}\text { Converting the information in electronic } \\
\text { communications services }\end{array}$ & 0.058 \\
\hline
\end{tabular}

According to (Figure 2) and (Table 2) and ranking research criteria, it has been identified that the most important criterion in "IT management in steel industries" cluster having (A) network code was "communicating with steel industries` costumers" having (AB) network code and network weight equal to 0.116; the most important criteria in "cloud computing capabilities" cluster having (B) network code were "reducing steel industries` costs" having (BA) network code and network weight equal to 0.226; and "providing rapid services to steel industries costumers" having (BB) network code and network weight equal to 0.142. on the other hand, the most important criteria in "developing electronic communications services" cluster having $(\mathrm{C})$ network code was "storing the data in electronic communications services" having (CD) network code and network weight equal to 0.148.

The following (Table 3 ) shows the fuzzy weights and rankings of the research criteria.

\section{Table 3.}

Fuzzy ranking of the criteria affecting cloud computing capabilities`analysis in developing electronic communications services

\begin{tabular}{ccccc}
\hline Rank & Research criteria & $\begin{array}{c}\text { Criteria`s } \\
\text { weight (based } \\
\text { on MCDM) }\end{array}$ & $\begin{array}{c}\text { Fuzzy weight } \\
\text { (based on } \\
\text { linguistic } \\
\text { variables) }\end{array}$ & $\begin{array}{c}\text { The final } \\
\text { weight of the } \\
\text { criterion }\end{array}$ \\
\hline 1 & $\begin{array}{c}\text { Reducing the costs of steel } \\
\text { industries }\end{array}$ & 0.226 & 0.8471 & 0.191445 \\
\hline 2 & $\begin{array}{c}\text { Storing the information in } \\
\text { electronic communications } \\
\text { services }\end{array}$ & 0.148 & 0.8286 & 0.122633 \\
\hline 3 & $\begin{array}{c}\text { Providing rapid services to the } \\
\text { costumers of steel industries }\end{array}$ & 0.142 & 0.8429 & 0.119692 \\
\hline
\end{tabular}




$\begin{array}{lcccc}4 & \begin{array}{c}\text { Communicating with the } \\ \text { costumers of steel industries }\end{array} & 0.116 & 0.8286 & 0.096118\end{array}$

In (Table 3), the final weight of the research criteria is the product of the criteria`s weight based on fuzzy weight MCDM (according to the linguistic variables).

\section{Discussion}

Finally, considering the fuzzy calculation related to the cloud computing capabilities in developing electronic communications services of the above table, the most important criterion in "IT management in steel industries" cluster having (A) network code was "communicating with steel industries` costumers" having $(\mathrm{AB})$ network code and fuzzy network weight equal to 0.096; the most important criteria in "cloud computing capabilities" cluster having (B) network code were "reducing steel industries' costs" having (BA) network code and fuzzy network weight equal to 0.191; and "providing rapid services to steel industries` costumers" having (BB) network code and fuzzy network weight equal to 0.120. On the other hand, the most important criteria in "developing electronic communications services" cluster having (C) network code was "storing the data in electronic communications services" having (CD) network code and fuzzy network weight equal to 0.123 since they had the highest fuzzy ranks in the programming environment of Matlab based on fuzzy logic calculations. Other analyses related to the research fuzzy ranking could be observed in the above figures and tables.

\section{Conclusion}

One of the most important results of this study regarding the investigation of the cloud computing capabilities in developing electronic communications services was that considering fuzzy calculations related to the cloud computing capabilities in developing electronic communications services, the most important criterion in "IT management in steel industries" cluster having (A) network code was "communicating with steel industries` costumers" having (AB) network code and fuzzy network weight equal to 0.096; the most important criteria in "cloud computing capabilities" cluster having (B) network code were "reducing steel industries` costs" having (BA) network code and fuzzy network weight equal to 0.191 ; and "providing rapid services to steel industries` costumers" having (BB) network code and fuzzy network weight equal to 0.120 . On the other hand, the most important criteria in "developing electronic communications services" cluster having (C) network code was "storing the data in electronic communications services" having (CD) network code and fuzzy network weight equal to 0.123 since they had the highest fuzzy ranks in the programming environment of Matlab based on fuzzy logic calculations. Iran has an international rank in producing steel so that in 2010, it was in the $17^{\text {th }}$ rank in the world, and nowadays, it has the $14^{\text {th }}$ rank among steelmakers of the world.

\section{Suggestions of the Study}

One of the most important suggestions of the current study was that managers and experts of steel industry of Yazd province should pay special attention to the performance status of "developing electronic communications services (A)" includes items such as: transmitting information in electronic communications services (the volume of information transmission, information transmission rate, information transmission type); restoring information electronic communications services (speed of information restoration, quantitative accuracy of information restoration, qualitative accuracy of information restoration); converting information in electronic communications services (converting the data to the information, converting the data to the knowledge, converting the knowledge to the wisdom); storing the information in electronic communications services (storing business information, storing costumers` 
information, storing competitors' information); and "cloud computing capabilities (B)" entailing items such as: reducing the costs of steel industries (reducing the costs of business in the hardware field, reducing the costs of business in the software field, reducing the costs of business in human resources field); improving flexibility and scalability of steel industries (providing rapid business responses to market changes, solving costumers needs in various scales, solving the needs of the business in various scales); providing speedy services to the costumers of steel industries (developing rapid services and products to customers, providing rapid services and products to the customers, providing services independently or as a group work); the variable "IT management in steel industries C)" includes items such as: communicating with costumers of steel industries (having better attitude from steel costumers, facilitating the payments among buyers and sellers, sharing organizational programs); increasing performance productivity of steel industries (easier use of new technologies, solving the existing complexities in the technology and business, integrity of applied programs in future); processing the information of steel industries (variations in informational subjects (qualitative), generalizability (quantitative) of the information, graphical analysis of the information) while taking strategic decisions since the most important current companies in steel industries of Yazd are:

Iran Alloy Steel Company in Yazd province is the greatest producer of various kinds of alloy steels in Iran and the Middle East; it is also one of the most modern companies in the world that produce alloy steels. The products of this company include the automotive industry, machinery, oil-gas and petrol, toll making, power plant, railroad, making medical and surgery tools as well as other industries.

Steel Industry Group of Yazd, as a productive and industrial subgroup of steel of Yazd, presents products such as simple and corrugated bars, industrial and constructional wires, fabric wide belts, girder, and ironstone, concentrate, bar truss, industrial gases, polished shaft, rotating shaft, and cold drawing shaft.

Milad rolling industries of Yazd has the national standard sign and annual production of 60000 tons of pipes and profiles that have been one of the greatest and equipped companies of profile production in the country and has provided the employment opportunity for 80 individuals in that years.

The subject of activity of Arfa Iron and Steel company in creating iron and steel companies and related units for developing Iran mine and mineral industries in determining points using the direct revival method, doing steeling actions using melting and moulding methods of iron steels and producing various geometrical standard pieces, establishing related units and dependent lateral and lower part and comprehensive industries to develop steel industry in an optimal way.

\section{References}

Jalali Aghdam D. \& Khademi Shoja M. (2018), Communications and differences of electronic trading and social trading, second national conference of knowledge and technology of Iran engineering sciences, Tehran: Symposia, 15(2): 119-132.

Doane Ashley N. (2016), Risky electronic communication behaviors and cyberbullying victimization: An application of Protection Motivation Theory, Computers in Human Behavior, 60(5): 508-513.

Bahremand H. \& Jalali Farahani A. (2014), Hearing electronic communications in Iran criminal law, MR journal, 21(3): 5-33.

Kim M. (2018), The role of multidimensional switching barriers on the cognitive and affective satisfaction-loyalty link in mobile communication services: Coupling in moderating effects. Computers in Human Behavior, 87(6): 212-223.

Al-Muhtadi J. (2019), Misty clouds-a layered cloud platform for online user anonymity in Social Internet of Things. Future Generation Computer Systems, 9(2): 812-829. 
Lussier M. (2016), The impact of a primary care e-communication intervention on the participation of chronic disease patients who had not reached guideline suggested treatment goals, Patient Education and Counseling, 99(4): 530-541.

Lin K. (2019), Data driven clustering for multimedia communication in Internet of vehicles, Future Generation Computer Systems, 9(4): 610-619.

Asadi A. \& Akbari M. (2018), Identifying the effect of electronic communications services in implementing costumer respect plan, intelligent business management studies, 16(4): 256-270

Roy P. (2012), Using Social Network Analysis to profile people based on their ecommunication and travel balance, Journal of Transport Geography, 24(8): 111-122.

Malekian N. \& Alipour R. (2012), The role pf electronic communications on organizational communications processes, Media studies, 18(7): 101-112.

Turkanović M. \& Gregor P. (2013), On the security of certain e-communication types: Risks, user awareness and recommendations. Journal of Information Security and Applications, 18(4): 193-205.

Zulkepli Zuraida H. (2015), Communication and Service Innovation in Small and Medium Enterprises (SMEs), Procedia - Social and Behavioral Sciences, 21(5): 437-441.

Yagoubi N. \& Shokuhi J. \& Jafari H. (2014), Identifying and ranking the key factors affecting the use of cloud computing in electronic health, Information processing and management, 30(2): 549-572.

Khatamzadeh M. \& Tajfar Gheisari A. (2016), Managing business assets using internet of things technology based on cloud computing, first international conference on the novel paradigms of intelligent trading and organizational management, Shahid Beheshti University, 18(5): 74-88.

Bruin X. (2018), Managing resources continuity from the edge to the cloud: Architecture \& performance. Future Generation Computer Systems, 79(3): 777-785.

Xia Q. (2017), The operational cost minimization in distributed clouds via community-aware user data placements of social networks, Computer Networks, 112(15): 263-278.

Sathya P. (2019), A sensor enabled secure vehicular communication for emergency message dissemination using cloud services. Digital Signal Processing, 8(5): 10-25.

Farhadian F. (2019), An efficient IoT cloud energy consumption based on genetic algorithm. Digital Communications and Networks, In press, accepted manuscript, 11(4): 137-146.

Jokar A. \& Berahmand N. (2009), Investigating electronic publication place in scientific communication of faculty members of Shiraz University. Education and learning studies (social and human sciences of Shiraz University), 15(2): 27-47.

Sheel Ghule M. \& Rupali Chikhale M. Kalpesh P. (2014), Cloud Computing in Banking Services, International Journal of Scientific and Research Publications, 4(6): 110-128.

Sadeqi H. (2010), Civil responsibility of intermediators and providers of electronic communications services, Private law studies, 40(2): 120-136.

Pedhadiya Mittal K. (2019), Device to device communication: A survey. Journal of Network and Computer Applications, 129(1): 71-89. 